\title{
La diferencia (de los idiotas)
}

\author{
Fernando Bárcena *
}

http://dx.doi.org/10.1590/0103-7307201507606

\section{Resumen}

El propósito de este artículo es pensar la singularidad de la diferencia desde el punto de vista de la 'diferencia de los idiotas', tomada esta expresión en el sentido original (idiôtés) del término: los seres carentes de una existencia política. El autor explora esta expresión, no en su mera abstracción conceptual, sino en su incidencia e invasión existencial a partir de la experiencia de la fragilidad y la vulnerabilidad, tal y como se muestran en la experiencia singular de un ser con discapacidad. Se busca pensar la diferencia como diferencia, tratando de pensarla en su singularidad, tal y como se pone de manifiesto ante nosotros, como si se tratase de un encuentro con la extrañeza, explorando, así, la experiencia de lo extraño, la cuestión de la impotencia, y la cuestión de la discapacidad en el debate filosófico-político actual. Bajo esta dimensión, el artículo cuestiona la lógica educacional que impone el deber de fijar en cada uno de nosotros un «alguien», un «quién» dotado de una identidad bien definida por los cánones de la normalidad, es decir, por los registros que dictan aquello que debe ser habitual, repetido o recto, de acuerdo con lo socialmente establecido y la imagen inmodificable y establecida de una norma.

Palabras-clave: idiocia, diferencia, vulnerabilidad, discapacidad, Deligny
* Fernando Bárcena Orbe, Catedrático de Filosofía de la Educación, Departamento de Teoría e Historia de la Educación, Universidad Complutense Madrid, Madrid, España. fernando@edu.ucm.es 


\title{
The difference (of idiots)
}

\begin{abstract}
This article aims to think the singularity of difference froms the point of view of I'll call the 'difference of idiots', taking this expression in the original sense (idiôtés) of the term: the beings without a political existence. The author explore this expression, not in his mere conceptual abstraction, but in its invasion and incidence in the existential experience of the fragility and vulnerability, such it is shown in the unique experience of being disabled person.
\end{abstract}

Keywords: idiocy, difference, vulnerability, disability, Deligny 


\section{Introducción}

El título de este texto no pretende ser una mera provocación. Decidí colocar entre paréntesis la expresión "de los idiotas", no porque pretenda ocultar una expresión que tantas veces se emplea de modo insultante, sino porque quiero referirme al particular modo de ser diferente de las existencias que, viviendo para sí, son, en su simplicidad, únicos. Mi título, entonces, hace referencia a la tentativa de pensar la singularidad, unicidad e incluso la abismable soledad de un ser que se presenta como lo "sin razón".

Lo que pretendo es pensar esa diferencia (en sí misma) pero distraída hacia los conceptos de "dependencia" y "fragilidad" y, de modo específico, con respecto a las vidas que, siendo dependientes de los adultos supuestamente "capaces" y "normales", se constituyen en existencias instaladas en cierta "improvisación existencial" (Malabou, 2000). Mi tema, entonces, es pensar la diferencia, considerada en el sentido aludido, en relación al sujeto discapacitado intelectualmente y que en la historia de las múltiples formas de nombrarlo fue enunciado, lo sabemos, como "idiota".

\section{Singularidad y diferencia}

En el prefacio de Différence et répétition, Gilles Deleuze, señala que el primado de la identidad define el mundo de la representación, y que el pensamiento moderno nace del fracaso de la representación y de la pérdida de las identidades: “El mundo moderno es el de los simulacros. Un mundo en el que el hombre no sobrevive a Dios, ni la identidad del sujeto sobrevive a la sustancia. Todas las identidades sólo son simuladas, producidas como un "efecto" óptico, por un juego más profundo que es el de la diferencia y de la repetición” (Deleuze, 2002, p. 1).

El simulacro de la identidad nos hace pensar que cualquiera de nosotros siempre es sustancialmente el mismo en cada gesto, en cada estado de humor, en cada tonalidad o en cada forma en la que aparecemos y nos hacemos visibles ante los demás (Skliar y Bárcena, 2013). Deleuze dice querer "pensar la diferencia en sí misma”, así como "la relación entre lo diferente y lo diferente", prescindiendo de las "formas de su representación”. Deleuze no lo dice así, pero quiero imaginar -voy a suponerlo, y a mi vez voy a intentar pensarlo- que cuando advierte de su intención (pensar la diferencia en sí misma, prescindiendo de las formas de su representación), lo que quizá se ofrece -y ésta no es más que una hipótesis- es la posibilidad de pensar la diferencia de acuerdo con la experiencia de la propia presencia de lo nombrado como diferente, 
o dicho en otros términos: la diferencia como lo que aparece o se torna manifiesto en sus propios términos, lo que se vuelve visible ante nosotros, en el seno de una relación o de un encuentro. 0 sea: que pensar la diferencia como diferencia es tratar de pensarla en su singularidad, tal y como se pone de manifiesto ante nosotros, como si se tratase de un encuentro con lo extraño.

Si existe una palabra que expresa clarividentemente la figura de lo "simple", de lo “particular”, o de lo “único”, es la palabra idiôtés (“idiotez”, “idiota”), término que, por derivación, designa la persona privada de inteligencia o al ser desprovisto de razón. Sabemos el significado que adquirió esta palabra en la Grecia clásica: designaba a la persona que, pudiendo atender la cosa pública, denotaba un profundo desinterés por ella, manifestando su debilidad en ese espacio. Iba a lo suyo, podría decirse, y parecía como encerrado en sí mismo. En el mundo griego, todo varón adulto libre es un hombre público (un igual entre los iguales) que disponía de una casa o de un hogar. La participación en la vida pública exigía de él, como condición principal, que se dominase a sí mismo; o sea, que ejerciese un control sobre lo que le pertenecía en la vida privada; mujer, hijos y esclavos constituían ese "sí mismo" que debía dominar. Propiamente hablando, entonces, el esclavo, la mujer y los hijos no tenían vida privada porque, de hecho, eran la vida privada del varón adulto libre. Esa forma de vida, que no es ni privada ni propiamente pública, esa vida que consiste en ser la vida privada de otro, la propiedad de otro, es lo que Agamben (2011) llama desnudez: una vida humana que consiste en carecer de existencia política.

Esta palabra, por tanto, evoca a los seres discapacitados mental o intelectualmente, y que se expresan en la simpleza de lo que son y que viven en sí y para sí. Esos seres de quienes se dice están desprovistos de inteligencia y razón son, o bien los que llegaron al mundo por nacimiento en su particular diferencia -con respecto a una norma que define al ser como ser provisto de inteligencia-, o bien aquellos que en algún momento devinieron otros por una especie de accidente que ninguna causa o antecedente explicaría suficientemente. Seres instalados en una suerte de improvisación existencial.

Una reflexión, en relación al concepto de diferencia, que toma como base de sus análisis la antigua noción de idiôtés, casi de modo necesario parece exigir algún tipo de anotación sobre la idea de la estupidez. Es cierto que una mirada, por fugaz que sea, del universo de racionalidad, ciencia, técnica de nuestro mundo actual produce cierta inquietud inmediata, pues bajo la apariencia de racionalidad al mismo tiempo 
constatamos una enorme carga de "estupidez", otra clase de crueldad, por no hablar de mezquindad, miseria y brutalidad. Esta es ciertamente una clase de estupidez. La otra tiene un componente distinto, pues no se refiere a un rasgo del carácter ni a una posición moral, sino que, de acuerdo con Deleuze, se refiere a "estructuras del pensamiento como tal" (Deleuze, 2011, p. 196). Todo pensamiento, cuando comienza su andadura, no puede ser sino estúpido, cometer múltiples errores. Pero como las fuerzas democráticas sólo valoran las competencias, en un sentido diluido del término “potencia” -que la reduce sólo al poder-de-hacer-, resulta que la experiencia de esa estupidez de la que habla Deleuze el sistema nos la devuelve en términos de castigo y culpa (Agamben, 2011).

Las anteriores consideraciones pueden inscribirse en un debate de carácter social y político que en los últimos años ha movido a algunos teóricos y filósofos de la política a incidir en los componentes, frecuentemente olvidados, de la vulnerabilidad y de la fragilidad de la vida socio-política. Parte del argumento que se pone en juego es que los niños y los adultos con graves deficiencias mentales son también, en el marco del espectro social y político, "ciudadanos", aunque de facto no participen en la decisión de los principios que están en la base del contrato social. No forman parte del cuerpo de los electores de estos principios. Esta elección requiere la existencia de una serie de capacidades (racionalidad, lenguaje, aptitudes mentales y físicas más o menos equivalentes) de las que ellos carecen o que están gravemente alteradas. De hecho, no hay ninguna doctrina del contrato social que, como señala Nussbaum (2007), "incluya a las personas con graves y raras deficiencias físicas y mentales en el grupo de los que deben escoger los principios políticos básicos” (p. 35). Hasta hace bien poco, estas personas simplemente estaban fuera de la sociedad; estaban excluidas, estigmatizadas, o eran escondidas en instituciones de beneficencia y abandonadas a su suerte. Estaban fueran de la esfera política. Eran idiotas, en la acepción griega de la expresión, por carecer de una implicación (y una visibilidad) en el orden político, social o público.

Ahora, algunos filósofos de la política contemporáneos están revisando las teorías contractualistas a fin de detectar sus puntos débiles y los "problemas no resueltos" de las teorías de la justicia social. Así, Martha Nussbaum (2007) propone lo que llama el "enfoque de las capacidades" -y en mi opinión insiste en el mismo mal que supuestamente quiere atacar- y sugiere que éstas se presenten "como fuente de los principios políticos para una sociedad liberal y pluralista” (p. 38). Por su parte, Avishai 
Margalit, antes que ella, defendió la tesis de que la tradición del liberalismo político no logra poner las bases para la construcción de una "sociedad decente", entendiendo por tal la "que no humilla a sus integrantes": "Una sociedad es decente -dice- si sus instituciones no actúan de manera que las personas sujetas a su autoridad crean tener razones para sentirse humilladas" (Margalit, 1997, p. 22). Y, por poner un último ejemplo, Judith Shklar propone pensar más atentamente las relaciones entre desgracia e injusticia y sugiere que la diferencia entre ambas "a menudo implica nuestra disposición y nuestra capacidad para actuar o no actuar en nombre de las víctimas, para culpar o absolver, para ayudar, mitigar o compensar, e incluso para mirar para otro lado" (Shklar, 2008, p. 28); en definitiva: la idea de que existe a nuestra disposición una regla simple y estable que separa la desgracia de la injusticia es algo así como una exigencia de seguridad moral que no puede ser satisfecha. Este texto tiene en cuenta -como un trasfondo- este tipo aportaciones, y más adelante insistiré un poco más en ello, y la sensibilidad que parece anidarse en sus respectivas propuestas.

\section{Extrañeza, impotencia, discapacidad}

Quiero referirme ahora a tres cuestiones que me parecen centrales: la experiencia de lo extraño, la cuestión de la impotencia, y la cuestión de la discapacidad en el debate filosófico-político actual.

Mi primera nota, tiene que ver con el concepto de "extrañeza", pues la percepción de una diferencia es siempre el encuentro con lo que nos resulta extraño. Así pues, ¿qué es lo extraño? ¿qué es lo excepcional? Sigo aquí un apunte de Bernhard Waldenfelds: "Si echamos una mirada a la historia de la filosofía -señala este autor-veremos que la filosofía occidental tradicional no le otorga ningún lugar central a lo extraño" (Waldenfels, 1998, p. 87). El “extraño" no ha sido, precisamente, una palabra de gran peso filosófico en la historia del pensamiento occidental. El extraño no es un mero extranjero, y su propia ambivalencia dificulta, de hecho, su definición exacta. Porque una vez que definimos lo extraño, lo normalizamos; deja de ser lo que es. Waldenfels destaca, a partir de la palabra alemana fremd, que se personaliza bien en el fremdling -el extraño, el extranjero- tres matices principales. En primer lugar, fremd es lo exterior, por oposición a lo interior, es decir, lo que aparece fuera del ámbito propio. En segundo lugar, es lo que pertenece a otro, frente a lo propio. Por último, se refiere a lo que es de otro género, lo inquietante o intranquilizador, frente a lo familiar. Tres pares de opuestos, entonces: exterior-interior; ajeno-propio; extraño-familiar. Lo extraño se 
muestra, entonces, como lo que se sitúa o se coloca en un lugar-otro, y es ahí, en ese extraño lugar, donde adquiere su significado radical, vinculado a momentos de lejanía, de ausencia o de inaccesibilidad.

Lo extraño, como lo que pertenece a un lugar lejano, ausente e inaccesible, es lo opuesto a ese otro lugar fijo que viene definido por un orden global estable, por un cosmos sin fisuras ni ambivalencia: "Mientras se tome como punto de partida un orden global, un cosmos inalterable o un orden firmemente establecido de la creación, todo lo que es, tiene su lugar." (Waldenfels, 1998, p. 88). El cosmos supone un mundo sin extrañeza ni ambivalencia, y es lógico, por tanto, que para un mundo así, a lo extraño, aún siendo inquietante, y precisamente por serlo, deba sometérselo a un proceso de normalización para desactivarlo. Lo extraño, anota Waldenfels, “no está en-otro-sitio del mundo, que pertenece a éste, sino que constituye un en-otro-sitio, un no-lugar (non lieu)". La experiencia de lo extraño es inquietante porque en ella encontramos una forma genuina de des-apropiación, de extrañamiento, experiencias éstas que son las condiciones de posibilidad de la hospitalidad: “El hombre no es sólo un ser que puede prometer, sino también un ser que puede acoger y albergar lo extraño." (Waldenfels, 1998, p. 93).

En este sentido, la experiencia de lo extraño tiene que ver con las fronteras externas que se desplazan hacia dentro: en lo extraño se da una suerte de extrañeza de nosotros mismos. El encuentro que relata Primo Levi entre el joven adolescente Henek, de quince años, y el infans sin palabra de tres años Hurbinek, constituye una auténtica experiencia de extrañeza, no porque Hurbinek sea otro ya localizado, sino porque Henek se vuelve enigmático para sí mismo como resultado de ese contacto con aquél. Es el otro extraño, en su extrañeza, quien hace de nuestra subjetividad y de nuestra identidad un enigma, el signo que nos adentra en esta experiencia de la des-apropiación. ${ }^{1}$ Por eso, la experiencia de la extrañeza es una experiencia del todo heterogénea, del todo discontinua, del todo extraordinaria, una experiencia que trasciende los órdenes existentes y conocidos, los modelos de relación canónicos. En el encuentro con lo extraño hay una relación del todo poética, hasta donde lo poético define un modo de relación que rompe con unas formas de relación instituidas. Por eso, la ambivalencia de la extrañeza sacude y vuelve inseguro el propio orden. La ambivalencia provoca que la extrañeza y la enemistad se aproximen, como se expresa bien con la palabra latina hostis, cuyo significado se da en la intersección entre la hospitalidad y la hostilidad.

1. Véase, Levi (2008, p. 262-264). 
Lo extraño es lo inconcebible, pues todo concebir es ya una forma de apropiación. Se trata de mostrar lo extraño, más que tener que o poder decirlo. Ante lo extraño, una primera respuesta puede ser el asombro, la admiración muda, la perplejidad. Lo extraño, por otro lado, puede producir miedo, pánico. En el primer caso -en el asombro-, lo extraño puede tornarse un problema a resolver, y en el segundo -en el pánico-, es un temor a eliminar. Asombro y pánico son afecciones perturbadoras de nuestros esquemas y de nuestras reglas, experiencias que nos desquician, que nos sacan de nuestro centro y de nuestro equilibrio. Son una forma de pathos, un padecer del que se aprende, una clase de conocimiento patético. Frente a lo extraño, sólo cabe, entonces, padecerlo, y después dar una respuesta. Lo extraño se ofrece como singularidad, como la experiencia de un acontecimiento, como una grieta que se abre al tejido del sentido. Como lo extraño no conoce ley que lo gobierne, el encuentro con lo extraño, y la respuesta a lo extraño, es por tanto ineludible: es una respuesta ante una situación que tiene una relación de concernimiento personal con nosotros. Lo extraño, en fin, deja su efecto siempre con posterioridad -sus efectos son inanticipables en el tiempo- de modo que entre las pretensiones de lo extraño y la respuesta hay una radical asimetría. Lo extraño, como lo no igual de lo que hablaba Nietzsche, no se puede equiparar con nada.

La diferencia hiere, y por eso nuestra primera reacción es negarla, tratando de normalizar su rareza. ¿Cómo combatir la imposición de la distinción normalidad-anormalidad?: pues habitando en el interior de la diferencia, siendo íntimo con ella. Con un gesto supremo de una reconciliación-otra, una reconciliación con el hecho de que nuestras contradicciones existen y no podrán ser resueltas en ningún orden superior. Se trata, entonces, de aprender a no negar la diferencia -aceptarla en su diferencia, en su singularidad, en su extrañeza, en su ambivalencia-, aprender a modificar la imagen de la norma. Éste es el paisaje que se puede abrir: tanto a quienes hacen de la diferencia una discriminación, como a quienes, para evitar una discriminación, niegan la diferencia.

Mi segundo matiz tiene que ver con la forma como se suele introducir la perspectiva de la diferencia (de lo diferente, de los diferentes, de las relaciones diferenciadas, etc.) en la reflexión educativa. Según Mario Perniola, “para la existencia de lo estético se hace esencial, al menos, la posibilidad del fin de un conflicto, de una paz venidera, de un momento pacificador en el que dolor y lucha se vean, sino definitivamente cesados, sí, al menos, momentáneamente suspendidos” (Perniola, 2001, p. 194-195). Tomando como pretexto esta afirmación, diré que la educación también comparte 
con la estética dicho requerimiento de perfección y de conciliación, que presenta dos caras: por una parte, cierta exigencia de (re)conciliación y, por otro, la afirmación reductiva de la idea (aristotélica) de la potencia.

El mencionado requerimiento de perfección, por un lado, se suele trasladar al ámbito pedagógico mediante un énfasis que privilegia lo normativo, al menos en dos sentidos básicos: primero, como prescripción en la conducción del sujeto a un estado más o menos idealizado de formación (acabamiento, plenitud); y, segundo, como actividad mediadora que no sólo se regula por reglas técnicas sino mediante principios, prescripciones y articulaciones de morales legitimadas en el orden social o en determinados marcos públicos legitimados. Dicha normatividad está comprometida con una mirada que, aunque acepta el pluralismo y admite pensar lo diverso, no es capaz todavía de abrirse a la singularidad de lo diferente. La aceptación de realidades tales como la diversidad, y otras, viene marcada por un fuerte componente clasificatorio previo, hasta el punto de que podemos decir, en otro orden de consideraciones, que no hay nada más ordenado que la biblioteca multicultural. La mencionada exigencia de perfección está asumida en un planteamiento que privilegia una noción normativizada de normalización de las conductas y de la vida por encima de las acciones espontáneas, que siempre marcan una “diferencia” más allá del reconocimiento de lo diverso. Bajo esta lógica, la educación se impone el deber de fijar en cada uno de nosotros un “alguien”, un “quién” dotado de una identidad bien definida por los cánones de la normalidad, es decir, por los registros que dictan aquello que debe ser habitual, repetido o recto (podríamos decir: prosaico) en cada uno de nosotros, de acuerdo con lo socialmente establecido y la imagen inmodificable y estatuida de una norma.

Mas, por otro lado, y con respecto a la afirmación reductiva de la potencia, la tesis de fondo de este escrito es que las elaboraciones teóricas y filosóficas sobre la educación -como, por otra parte, sobre la moral, la política o el derecho-, al haber partido de un concepto normativizado de normalidad, han despreciado el hecho de que lo que los humanos compartimos es nuestra mutua fragilidad y dependencia, o dicho en otros términos, nuestra impotencia: no nuestro poder-de-hacer, sino nuestro poder de no-hacer (que es otro modo de estar en lo vulnerable). En definitiva, la filosofía y la teoría de la educación han partido de un concepto restrictivo de potencia, que tiene su propia "desventura”, ese poder de no-hacer extraña y magníficamente expuesto en la casi indescifrable fórmula del "discapacitado" Bartleby: "I would prefer not to do it" (Melville, 2011). 
En efecto, si recurrimos a la filosofía de Aristóteles encontramos, en la Metafísica, la definición que nos da la potencia (dynamis) como algo estrechamente vinculado a la "impotencia” (adynamía). Toda potencia es, al mismo tiempo, impotencia de lo mismo y respecto de lo mismo: de lo que es potencia (Aristóteles, 2001, 1046a, p. 2931). 0 lo que es igual: todo "poder de hacer" es, siempre, un "poder de no-hacer", de modo que lo que define la potencia humana es simultáneamente potencia de ser y de no ser, de hacer y de no-hacer. Esto expone al hombre, por supuesto, al riesgo del error, pero a la vez le permite acumular y dominar libremente sus propias capacidades, y transformarlas en facultades.

De este modo, la tendencia "psicologizante" de algunos discursos pedagógicos ha contribuido a reforzar el punto de vista según el cual, en palabras del escritor portugués Vergílio Ferreira, hablar de un tímido, de un loco o de un colérico es referirse a una manera rara o vulgar de ser, y no "hablar de las múltiples formas que una realidad anterior puede llegar a asumir. Ser loco es ser alguien que es loco, ser tímido es ser alguien que se caracteriza por la timidez" (Ferreira, 2003, p. 70). Somos únicos en la persona que somos y múltiples en las formas de nuestra expresión. Bajo el imperativo de la normalidad, lo que se presenta al mundo y a los otros como lo radicalmente diferente es una perturbación que, al serle recordada de continuo al sujeto, provoca un cierto sentimiento de culpa que lleva a querer deshacerla por asimilación al principio de normalidad ya establecido. Podríamos decir, entonces, que la ilusión de normalidad apacigua la perturbación de la diferencia como presencia singular y problemática en el mundo. En otro plano, pensemos la experiencia de la singularidad de aquellos seres cuya mirada, cuya escucha y cuyo cuerpo es lo otro, lo no normalizable que, pedagógicamente, buscamos sin embargo normalizar, haciendo entrar lo diferente en sociedad. El poeta René Char los mostró poéticamente de este modo: “Algunos seres no están ni en la sociedad ni en una ensoñación. Pertenecen a un destino aislado, a una esperanza desconocida. Sus actos aparentes se dirían anteriores a la primera inculpación del tiempo y a la despreocupación de los cielos. Nadie se ofrece para pagarles un salario. Ante su mirada se funde el porvenir. Son los más nobles y los más inquietantes" (Char, 1989, p. 85).

Como ya señalé -y ahí va la última cuestión-, el tema que propongo discutir tiene implicaciones filosóficas para la ética, la política, el derecho y, por supuesto, la educación. No pretendo cubrir todos estos aspectos, así que me conformaré en inscribir mis reflexiones en una filosofía de la educación. Las implicaciones políticas, morales 
o jurídicas relativas a lo que suele denominarse el "respeto a las diferencias" o en tópicos tales como la "lucha contra la exclusión” suelen tener como su filtro central, o su campo fundamental de pruebas, el escenario educativo.

Martha Nussbaum, al revisar las limitaciones de las teorías liberales del tipo de las de John Rawls, señala que "una teoría satisfactoria de la justicia humana debe reconocer la igualdad de los ciudadanos con deficiencias, incluidas las deficiencias mentales, proveer adecuadamente para su asistencia y educación” (Nussbaum, 2007, p. 110). Al observar en qué medida el caso de las deficiencias mentales constituyen una limitación para ese tipo de teorías liberales de la justicia, Nussbaum insiste en que “el eje práctico de mi argumento será la educación”, tanto en lo que se refiere a los niños como a los adultos.

Por mi parte, no pretendo hacer de la educación simplemente un laboratorio de pruebas en orden a mostrar en qué medida las aludidas teorías manifiestan sus más evidentes limitaciones, que las tienen. De modo específico, Rawls es consciente de que su teoría se centra en unos casos y margina otros y, así, señala: “Todos los ciudadanos son miembros plenamente cooperantes de la sociedad a lo largo de una vida completa. Esto significa que todas las personas tienen suficientes facultades intelectuales para participar de forma normal en la sociedad, y que nadie sufre necesidades atípicas que resulten especialmente difíciles de satisfacer, como por ejemplo, unas necesidades médicas atípicas y costosas" (Rawls, 1980, p. 546). Rawls reconoce que la satisfacción de tales necesidades es “una cuestión práctica urgente”, pero, insiste, en un estado inicial el problema de la justicia social se ha de plantear "entre aquellos que participan de forma plena, activa y moralmente consciente de una vida completa" (Rawls, 1980, 546).

Lo que deseo hacer, al volver a plantear la cuestión de la diferencia desde el ángulo de lo frágil y de la dependencia, es volcar cierta dimensión crítica sobre el concepto de identidad heredado -el mismo que está en la base del planteamiento de Rawls, por ejemplo- en la educación, uno que define sus contornos excluyendo. Por muy atractiva y defendible que sea la idea según la cual "mi identidad se define por los compromisos e identificaciones que proporcionan el marco y horizonte dentro del cual yo intento determinar, caso a caso, lo que es bueno, valioso, lo que se debe hacer, lo que apruebo o a lo que me opongo" (Taylor, 2006, p. 52), la misma no deja de ser sino una construcción profundamente racionalista de la identidad humana y, más allá de este componente, una visión que hace depender la comprensión del yo humano de una 
permanencia inmodificable del ser. Y esto, quiero insistir en ello, tiene implicaciones fortísimas desde el punto de vista de una filosofía de la educación y de la formación humana; pues todo el edificio conceptual de la educación se hace depender de las supuestas sólidas bases de esa comprensión del yo, siendo el caso específico de las necesidades atípicas de los discapacitados mentales tan sólo "una cuestión práctica urgente", como sugiere el propio planteamiento de Rawls.

Podría decirse, entonces, que dicha comprensión del "yo moderno", por decirlo con Taylor, no remite sino a un orden idealizado frente al cual el caso de las identidades frágiles no constituye sino un desorden, o quizá una desviación despreciable. Frente a esto, sería ventajoso recuperar el comentario que el propio Deleuze hace del bergsonismo, cuando, al comentar algunas ideas de Bergson, sugiere que "la idea del desorden aparece cuando, en lugar de ver que hay dos o varios órdenes irreductibles [...] se retiene solamente una idea general del orden que se conforma con oponerse al desorden y pensar en correlación a la idea de desorden” (Deleuze, 1996, p. 9).

La lectura de la diferencia que propongo pensar tiene que ver con este tipo de referencias. Tengo presente, por ejemplo, lo que Clément Rosset denomina crueldad de lo real: lo real tiene un carácter único, singular, inapelable e irremediable; lo real es lo que es, y no vale, entonces, tratar de explicarlo desde criterios, principios o categorías que estén más allá de lo real mismo, pues de seguir esta estrategia no haríamos sino decir la realidad desde un principio articulado en una serie de categorías situadas exteriormente a la misma: idea, alma, espíritu del mundo, incluso "diferencia" (Rosset, 1994, p. 22). Las cosas, pues, existen en forma idiota. Y aquí lo "idiota" no es meramente una "debilidad del espíritu" sino que define un ser en la proximidad de la idiocia de lo real. Es simplicidad sin dobleces. Si lo real es único -"singular" y "sin doble"-, ello significa que sólo hay una realidad, y no dos (visible/invisible; apariencia/verdad; sensible/inteligible, etc.); o insistiendo de nuevo en la fórmula de Rosset: que lo real es idiota, algo en lo que la razón o las dobles intenciones brillan por su ausencia; que lo real es, en fin, lo particular, lo solitario y lo insólito (Rosset, 2004, p. 13).

\section{Poética de la vulnerabilidad}

De inmediato, el universo de Fernand Deligny es, en todo esto, una auténtica provocación: o bien creemos, como señaló con frecuencia el propio Deligny, que el autismo, diferencia absoluta donde las haya, es un atentado (neurológico, psíquico, mental, orgánico) a la integridad del desarrollo de un ser -y en ese sentido queda constituido 
como una enfermedad, como una anormalidad o un desvío que requiere pautas médicas y terapéuticas-, o bien consideramos que el autismo es una modalidad de ser, de ser un sujeto, al que "il faut le laisser être", lo que implica acogerlo en su singularidad y rechazar cualquier forma de normalización, portadoras todas ellas de algún grado de segregación. La crítica del lenguaje, esparcida a lo largo de toda su obra, llevó a Deligny a vivir con niños psicóticos y autistas, y justificó su rechazo a toda forma de intercambio con ellos mediante la palabra colocando a lo real por encima de todo:

Otro término instituido: curar. Está 'enfermo', ese chico. Su 'enfermedad' incluso tiene un nombre provisto de la h y la i de rigor cuando es grave. ÉL está gravemente afectado. Ese ÉL de la tercera persona atribuido de entrada a un niño cuya 'enfermedad' es precisamente no ser 'yo' siempre me ha parecido sospechoso. Ese ÉL, aunque sea ficticio, no deja de aguantar lo que le echen. No trata de ser un lugar de vacantes ${ }^{2}$ (vacaciones), salvo la del lenguaje. No se trata de curar. Nuestro proyecto consiste en arremeter contra las palabras y sus abusos (Deligny, 2009, p. 48).

Cuando el acceso a la palabra queda definitivamente comprometido, pretender colocarla de nuevo en la relación con estos chicos es alejarlos aún más del mundo de lo que puede decirse y nombrarse. La película Ce Gamin, là (1975), realizada por Renaud Victor, y con una voz en off basada en un escrito del propio Deligny como acompañamiento de las imágenes, habla -si así puede decirse-, de Janmari, que en 1967 tenía 12 años, y que la psiquiatría define así: “incurable, insoportable, invivible, incurable". No se trata, para Deligny, de que Janmary pueda vivir su vida, sino "una vida”. Pero, a su vez, el gesto de Deligny es, también, una cierta manera de agrupamiento (él vive con autistas y psicóticos) y, podríamos decir, de segregación o de apartamiento. El sentido de la apuesta de Deligny queda especificado por él mismo en su escrito “La tentative”, del año 1975:

El sentido de nuestra iniciativa no es el de crear, más o menos a largo plazo, una institución, ni siquiera 'abierta', sino, muy al contrario, hundirnos los unos en los otros en modos de vida a nuestra conveniencia, tratando de 'ver' qué 'deriva' intervenía, sin nosotros saberlo, en nuestras maneras de ser, nuestros 'mínimos gestos', por el hecho de la presencia, ahí, permanentemente, de unos niños visiblemente "aparte" (Deligny, 2009, p. 45). vacance(s) significa tanto "vacante" como "vacaciones". 
Deligny, pues, habla de la presencia (Bárcena, 2012). Me pregunto si esta presencia, completamente al margen de todo deseo de normatividad y regulación, se puede producir de algún modo y qué supone la misma. En Deligny hay, al parecer, una especie de poética: una mirada singular sobre esos niños, una disposición en esa relación con ellos, en definitiva, un estar presente ahí, con ellos.

Pero para quien esto escribe, la lectura de la obra de Deligny es un ejercicio muy duro. Lo entiendo y no lo entiendo; lo acepto y me resulta insoportable. Me contradice y le contradigo. Cuestiona mis hábitos como padre acostumbrado (?), hasta la obsesión, por un hijo discapacitado al que nunca supo cómo nombrar, y con quien tuve que aprender a vivir, aunque protegiendo al mundo de su presencia. Un ser que es y no es; ni es "a-normal”, ni "normal”, ni "autista”; y, sin embargo, en infinitos y discretos gestos -pero llamativamente visibles en su invisibilidad- se comporta como tal: como si su genética le hubiera impuesto la herida autística que no acepto y aprendo, sin embargo, a decirme. La constituyo en la prosa de mi vida. Habla, con una voz incesantemente repetida en sus fórmulas aburridas y prodigiosas, y de vez en cuando, enredadas con las palabras, se atisba un talento de extrema sensibilidad muda. Sus dos manos, repetidamente llevadas hacia su frente cada vez que quiere decir lo que no entiende, parece dibujar las palabras que le faltan en su rostro, y me dejan mudo: “A ver, déjame que piense, déjame que piense, a ver si me acuerdo, lo que me pasa, lo que me pasa, es, es, es....". Me agarro a la silla, a lo que sea, para forzar mi silencio, para contenerme e impedirme hablar por él, para no tener que ser yo quien, de nuevo, como siempre, ponga en sus manos las palabras que no salen por su boca. Leo a Deligny:

Tengo una clase de niños retrasados en un inmenso hospital psiquiátrico en Armentières, en la región del Norte. Son unos quince en una sala de paredes claras, con bonitas mesitas nuevas, y yo soy su maestro. Quince idiotas en delantal azul y yo maestro en el rumor de este caserón de seis pisos que contiene seiscientos o setecientos niños retrasados. En el rumor de este caserón lleno de gritos extraños, y su vez en el ruido ahora casi universal de la guerra (Deligny, 2009, p. 35)

Deligny escribe estas palabras, claras y secas, en su Diario de un educador. La entrada tiene esta fecha: junio de 1941. Rumor de guerra. Gritos de quince idiotas sobre 
fondo de una estupidez bélica. Y pronuncia palabras que nuestra tranquila conciencia democrática y políticamente correcta repudia. Pero nosotros hablamos: él está con ellos. "El menor gesto tiene una historia", dice en otra entrada de su Diario:

Es verdad -escribe en noviembre de 1965- que estos niños retrasados en este castillo de Sologne viven totalmente fuera del tiempo y del espacio, perdidamente apolíticos, y esta es la recompensa del destino: viven tranquilos en un castillo del siglo XIII. Libres. Son libres. Pueden expresarse libremente mediante toda clase de onomatopeyas. Ni siquiera están obligados a usar las palabras tal como son. Tienen acuarelas y lápices para expresarse, una vez más, libremente. No necesitan el menor gesto útil. Jubilados de nacimiento (Deligny, 2009, p. 35).

Deligny aparta a sus chicos de la sociedad. ¿Lo hace para devolver cosido a la sociedad lo que nació roto? No lo creo. Pero él escucha a sus críticos. Uno de ellos espera que Deligny, finalmente, se encuentre con algún médico "entusiasta de la fisiología" para que trabaje con él. De lo contrario, insiste el comentador, "el uno escribirá una novela, el otro un tratado de medicina, pero ni el uno ni el otro habrán comprendido y ayudado plenamente a los niños que les fueron confiados" (Deligny, 2009, 40). La dureza de Deligny tiene un motivo: lo que quiere es ayudar, no amarlos. Lo dice en Semilla de crápula: "Si es que te quieren, regálales golosinas. Pero el día que vengas con las manos vacías te llamarán cerdo asqueroso. Si quieres hacer tu trabajo, dales una cuerda para estirar, leña para partir, sacos para trajinar. El amor vendrá después, y no es esta tu recompensa" (Deligny, 2009, p. 18).

Nosotros, envueltos en palabras, quizá encontremos en Deligny un gesto distinto: un modo de ser enteramente fuera del lenguaje. Deligny busca una lengua equivalente a las formas artísticas -poesía frente a discurso-, a los gritos y a las estereotipias, como queriendo tomar partido a favor de las cosas y contra la transparencia de los signos. Quita de la relación, de una relación instalada en la total extrañeza, lo que hace que lo extraño lo sea aún más: quita el peso del lenguaje. El texto que acompaña a Ce Gamin, là es como un poema. La composición de este texto no me parece que responda a una cuestión de búsqueda de estilo. Es coherencia: "Hablar / como si fuera lo más natural / hablar, hablar de ese chico y de los demás que se le parecen / cuando nosotros hemos hecho todo lo posible para prescindir del lenguaje /de ese dichoso lenguaje que nos hace lo que somos / y ahora hay que rendirle cuentas / 
mutista /ese chico / ¿entonces de qué fiarse / de qué fiarse /cuando el lenguaje / falta?” (Deligny, 2009, p. 68)

Yo creo que el “Universo Deligny” es poético. Y aquí lo poético tiene un trato, una insistencia y una intimidad con lo otro como otro (pero no lo teoriza), con lo roto y lo inasumible (sin erigirse en salvador de vidas rotas). La poética de Deligny es una poética de la presencia: uno debe estar presente, con los chicos, sobre todo cuando no está allí, dice (Bárcena, 2103). Quizá por eso dice las cosas como las ve y las trata. Pues el nombre, a él, no le importa. Le importa colocar nombres y adjetivos en medio de una relación en la que el lenguaje aleja aún más a los chicos del mundo. La relación se llena de cosas. De objetos. De haceres. ¿A quién quiere, si lo quiere, ayudar Deligny? ¿A esos chicos? No lo tengo claro. En el fondo, me parece que Deligny quiere ayudarse a sí mismo, o ayudar a los educadores a quienes dirige sus reflexiones. En muchos de sus escritos, que son duros, hay una especie de exigencia, de normatividad implacable. Les dice (a sus lectores, muchos de ellos educadores), y muy seriamente que, bueno, "haz lo que quieras, pero si haces esto y lo otro te irá mal. Piénsatelo dos veces".

Y también está el asunto de la distancia. Hay muchas cosas aquí. Por ejemplo, la moral (y la educación moral y todo eso de los valores que se predican o que se imponen o que se sugieren) tiene que ver con la distancia entre las gentes. Hay cosas que disminuyen la distancia y cosas que la aumentan. Cuando se habla en términos, digamos, supuestamente amorosos, y se invocan palabras como "compasión" o "piedad" u otras, parece que la distancia moral entre las personas se diluye, y cuando se proponen otras, como la palabra "virtud" o “juicio", la sensación es de mayor alejamiento. Esas primeras palabras parece que son voces distintas que enuncian el mismo fenómeno moral de base: el bien consiste (y aquí el bien es ser compasivo o piadoso, o lo que sea) en disminuir la distancia con el otro en su favor. Pero Deligny no habla ni de unas ni de otras. Simplemente dice: quédate ahí, hazte presente y haz cosas con ellos.

¿Qué supone, en fin, la existencia de un mundo vulnerable para el pensamiento, para una filosofía y para la misma filosofía de la educación? ¿Se trata acaso sólo de un pre-texto para que la filosofía renueve sus contenidos, los objetos de su reflexión? ¿Qué supone para una reflexión pedagógica la vida frágil del deficiente mental, más allá del hecho de que tenerlo en cuenta muchas veces no pasa de ser sino una nueva ocasión para tranquilizar nuestra conciencia social autocomplaciente? 
Veamos: una vida, tan concreta y singular como la de cualquiera de nosotros, en la que alguien confunde constantemente la realidad y la ficción, y eso le hace sufrir; no ser capaz de desarrollar un razonamiento lógico, ni comunicar con el lenguaje lo que se desea o lo que le pasa. Verse incapaz de adivinar, en el otro, si hay engaño o una tentativa de ayuda; no poder controlar los propios arrebatos emocionales, o los impulsos, y en cualquier momento cometer constantes errores pragmáticos de contexto; no tener impulsos ni deseos sexuales, a una edad en la que cualquier joven los tiene, o por el contrario ser incapaz de canalizarlos. La lista se puede ampliar casi hasta el infinito. ¿Conmueven, movilizan cada una de estas señales de lo frágil de una vida al pensamiento, a la filosofía, entendida como tal, es decir, como filosofía? ¿No aspira la filosofía a la verdad, no enseña a razonar con coherencia, no dispone de instrumentos para aprender a distinguir la realidad de la ficción, no nos habla de la vida emocional, o de los afectos y las pasiones, de la sexualidad o del otro, de la vida moral o de la vida política? Sí, lo hace. Y además busca universalizar sus proposiciones. Habla de lo real; pero ¿habla también de los reales, de las realidades y de los tiempos múltiples? ¿Qué lugar ocupan las subjetividades molestas en una conciencia filosófica segura de sí misma? ¿lnquieta de algún modo? 


\section{Referências bibliográficas}

Agamben, G. (2011). Desnudez. Barcelona: Anagrama.

Aristóteles (2001). Metafísica. Madrid: Gredos.

Bárcena, F. (2012). Una pedagogía de la presencia. Crítica filosófica de la impostura pedagógica. Teoría de la educación. Revista interuniversitaria, 24(2), 25-57.

Bárcena, F. (2013). Poética de la espera. Una filosofía íntima (con fragmentos de Proust y Pizarnik). Kamchatka, 1, 213-238.

Char, R. (1989). El desnudo perdido. Madrid: Hiperión.

Deleuze, G. (1996). Le bergsonisme. Paris: Puf.

Deleuze, G. (2011). Différence et répétition. Paris: Puf.

Deligny, F. (2009). Permitir, trazar, ver. Barcelona: MACBA - Museu d'Art Contemporani de Barcelona.

Ferreira, V. (2003). Invocación a mi cuerpo. Barcelona: El Acantilado.

Levi, P. (2008). La tregua. In P. Levi, Trilogía de Auschwitz. Barcelona: El Aleph Editores.

Malabou, C. (2000). Ontologie de l'accident. París: Éditions Leo Scheer.

Margalit, A. (1997). La sociedad decente. Barcelona: Paidós.

Melville, H. (2011). Bartleby el escribiente. In J. L. Pardo, Preferiría no hacerlo. Valencia: Pre-Textos.

Nussbaum, M. (2007). Las fronteras de la justicia. Consideraciones sobre la exclusión. Barcelona: Paidós.

Perniola, M. (2001). La estética del siglo XX. Madrid: Antonio Machado Libros.

Rawls, J. (1980). Kantian Constructivism in Moral Theory. Journal of Philosophy, $77,515-571$.

Rosset, C. (1994). El principio de crueldad. Valencia: Pre-Textos.

Rosset, C. (2004). Lo real. Tratado de la idiotez. Valencia: Pre-textos.

Shklar, J. (2008). Los rostros de la injusticia. Barcelona: Herder.

Skliar, C., \& Bárcena, F. (2013) Cartas sobre la diferencia. Una cuestión de palabras (entre la amistad, la incomodidad y el sinsentido). Plumilla educativa, 12, 11-28.

Taylor, C. (2006). Fuentes del yo. La construcción de la identidad moderna. Barcelona: Paidós. 
Waldenfels, B. (1998). La pregunta por lo extraño. Logos. Anuario del Seminario de Metafísica, 1.

Submetido à avaliação em 24 de julho de 2014; aprovado para publicação em 26 de janeiro de 2015. 